University of Nebraska - Lincoln

DigitalCommons@University of Nebraska - Lincoln

Faculty Publications - Textiles, Merchandising and Fashion Design

Textiles, Merchandising and Fashion Design,

Department of

2020

Make and break details: The architecture of design-build education

Claire Nicholas

Arlene Oak

Follow this and additional works at: https://digitalcommons.unl.edu/textiles_facpub

Part of the Art Practice Commons, and the Industrial and Product Design Commons

This Article is brought to you for free and open access by the Textiles, Merchandising and Fashion Design, Department of at DigitalCommons@University of Nebraska - Lincoln. It has been accepted for inclusion in Faculty Publications - Textiles, Merchandising and Fashion Design by an authorized administrator of DigitalCommons@University of Nebraska - Lincoln. 


\title{
Make and break details: The architecture of design-build education
}

\author{
Claire Nicholas \\ Department of Textiles, Merchandising \& Fashion Design, \\ University of Nebraska-Lincoln, United States \\ Arlene Oak \\ Department of Human Ecology, University of Alberta, \\ Edmonton, Canada \\ Corresponding author: Claire Nicholas cnicholas2@unl.edu
}

\begin{abstract}
In the imagination of prominent architects and architectural theorists, the detail figures as both a promising and perilous element of built form. This paper explores the tension of the "make or break" qualities of the architectural detail(s) in the learning and doing of design, through an ethnomethodologically informed ethnography of North American design-build architecture education. The discussion parses three episodes which highlight the generative qualities of the detail, in terms of its pedagogical value for architecture, and as a heuristic for the study of design practice. As both the material process of joining disparate elements, and a locus for complex social and professional relations and meaning making activities, the assembly of the detail is inherently messy, though productively so.
\end{abstract}

Keywords: architectural design, design education, collaborative design, design knowledge, ethnography

Published in Design Studies 66 (2020) 35-53

DOI: https://doi.org/10.1016/j.destud.2019.12.003

Copyright (C) 2020 Elsevier Ltd. Used by permission 
In the imagination of prominent architects and architectural theorists, the architectural detail figures as both a promising and perilous element of built form. As related by Marco Frascari (1984), the celebratory adage, "God is in the detail" is commonly (though misleadingly) attributed to the giant of modernist architecture, Ludwig Mies Van der Rohe (p. 23). Louis Kahn, in his poem dedicated to the work of his friend Carlo Scarpa, notes, "The detail is the adoration of Nature" (McCarter, 2005, p. 303). Design icons like Charles Eames have drawn parallels between the role of the detail in architecture and product design, "The details are not details e they make the product just like details make the architecture" (Eames, 2015, pp. 224e225). The perhaps more well-known or mainstream version of the saying (at least since the 196os) e "the devil is in the details" e though not specific to the architectural context, points to a darker vision of the detail's potentialities.

This paper approaches these seemingly diametrically opposed understandings of the architectural detail in empirical terms, exploring the tension of the "make or break" qualities of the role of the detail(s) in the doing of design. Our discussion builds on the definition of the detail as both a structural and symbolic connection. According to the first sense of the word, the architectural detail is the juncture where disparate materials come together ("detailing" describes the process of ensuring that this joining performs its intended function) (Baudoin, 2016; Ford, 2011; Frampton, 1995). In the latter sense, the detail is the minimal unit of architectural meaning, where signification is joined to built structure (Frascari, 1984, p. 23). Whereas much architectural writing on the material and symbolic aspects of the "detail" considers its role in the built work of individual architects (Baudoin, 2016; Burry, 2014; Ford, 2011; Frascari, 1984), we argue that these disciplinary understandings tend to overlook the social construction of details (in both the material and symbolic sense) in situated practices unfolding in real time. We explore this issue on site, so to speak, through an ethnomethodologically informed ethnography of architecture education. We are particularly attentive to the relationship between discursive practice and other forms of action (such as working with tools and materials) (Holstein \& Gubrium, 2007; Nicholas \& Oak, 2018; Oak, 2011, 2012), chap. 19; Murphy, 2012; Suchman, 2006). To enable this analytical approach, we audio and video recorded the 
everyday experiences of architecture students, their professors (who were also professional architects), and other participants as they went about the work of designing, making, teaching, and learning. Our discussion focuses on "design-build" education (also known as "Live Projects" in the UK (Anderson, 2014)). The key feature of designbuild is that it enlists students in realizing structures at full scale. While the projects are usually relatively modest in size and in terms of their infrastructural complexity (e.g. plumbing, electricity, heating, ventilation, and air conditioning), they nevertheless require that students engage with "real" clients, engineers, subcontractors, budgets, and the material and social construction of real architectural details.

The popularity of design-build courses within traditional architecture curricula is on the rise, in North America and beyond (Kraus, 2017). Design-build offers an experience that differs significantly from most architecture education, wherein the majority of projects are, inevitably, hypothetical. In traditional studio-based courses, students draw and make models of structures that will never be built, due to the complexity, expense, or time involved. The hypothetical aspect of standard architectural education, and its emphasis on imaginative experimentation, challenges students to invent what might be possible, rather than to actually make it. In design-build coursework, students create the design artifacts typical of any studio course: hand sketches, physical scale models, digital models, technical drawings, occupation drawings, etc. But they also follow the full arc of project delivery including navigating client relations, working with engineers, developing construction documents and detail drawings, securing building permits, tackling project management and budgeting (even fundraising), and finally assembling the full-scale structure on a "real" construction site.

The inherently transversal approach of design-build pedagogy affords it a unique position vis-a-vis the discipline of architecture, institutions of higher learning, and broader publics. Design-build projects bridge the design studio, physically sited in the specialized setting of an educational institution (Farias \& Wilkie, 2016), and locations accessible to the general public. This academic public dialogue is the intention of design-build course projects and factors into learning objectives (Hardin, Eribes \& Poster, 2005; Harriss \& Widder, 2014; Kraus, 2017; Rockhill \& Kraus, 2017; Verderber, 2019). Notably, this 
"in between" position of design-build carries technical and ethical implications for the field and its practitioners. As discussed later in this paper, design builders embrace a full-bodied and often messy engagement with materials, craft and technical know-how, and the social or relational elements of designing with and for others. In large part, then, the ethos or culture of design-build education recognizes the interdependent and contingent nature of architecture in the world (Ingold, 2013; Till, 2009; Yaneva, 2009, 2012). The heuristic of the "detail" is therefore a good fit.

The empirical material for this paper is drawn from a five-year long, Canadian-funded research-creation project involving four North American design-build architecture education programs. Each program was charged with designing and building a grid shell structure. Projects included a cover for a farmer's market, a pavilion for an art park, a shade structure on a university campus, and a multi-purpose interpretive and activity center in a Canadian national park. A gridshell is defined structurally as possessing "the shape and strength of a double-curvature shell, but made of a grid instead of a solid surface" (Douthe, Baverel, \& Caron, 2006, p. 1). The basic form has been likened to a soap bubble, and in the contexts of architecture education, it is often categorized as a curved shelter or pavilion made of either a timber or metal lattice that forms the roof, or the roof and a substantial portion of the walls. On the one hand, the gridshell is associated with iconic structures in the history of architecture, exemplified in buildings such as Frei Otto's Mannheim Multihalle (1974) (Liddell, 2015). On the other, within what theorists Oxman \& Oxman (2010) have termed the "new structuralism" paradigm in architecture, the gridshell poses unique contemporary challenges for architects, engineers, and the craftspeople who build them (Chilton \& Tang, 2016). Indeed, architectural educators (Cavanagh, 2013; Chilton \& Tang, 2016; Malek, 2012; Tang, 2013; Verderber, Cavanagh, \& Oak, 2019) have cast the gridshell as a particularly intriguing research object for the exploration of how emerging technologies and practices associated with "digitally mediated architecture" (Oxman, 2007, p. 100) might be paired with recent timber fabrication technologies and experimental pedagogies such as design-build. The innovative nature of the gridshell is central to our discussion, since there are no standardized design guidelines or settled precedents that architects can follow in either designing or building these structures. 
As field sites, the design-build architecture education programs we followed drew our attention to the phenomenon of the detail, both as the material practice of joining disparate elements, and as the locus for complex social and professional relations. In short, practices of detailing reveal the integral roles of both social and material tectonics in the "art of joinings" (Frampton, 1995). Just as relevant for our discussion, design-build highlights the productive pedagogical and analytical potential of details that resist easy or stable joinings e producing friction and what Chad Kraus (2017) has called, "salutary failure" (p. 105) (See also Gjertson \& Trumble, 2014). It does so in two ways. First, design-build learning and related paradigms of architectural expertise privilege encounters with (and ideally mastery of) diverse design media and materialities, encounters which mimic elements of the entire arc of design and construction processes. Second, designbuild education entails collaboration among peers and with a broad spectrum of outside stakeholders with varying investments in the construction of the built environment.

In the first instance, therefore, design-build education foregrounds the importance of grappling with the implications of material and technical joinings (and how to allow for or "tolerate" their differences) in a hands-on and embodied manner. In the second instance, it prompts students, faculty and other stakeholders to negotiate the joining of architecture as a profession and a field of knowledge with other ways of knowing - in practice. In other words, questions of professional ethics, relationships to proximate domains of expertise (such as engineering), and authority over or ownership of a built structure are performed in situated social interactions. These include settings such as design meetings in classrooms and on construction sites, the fabrication of prototypes in university design labs and workshops, the semi-public presentations and discussions of designs in the juried review or "crit," and even the ostensibly solitary activity of digital modeling or technical drawing in a studio setting. Very little of design-build education is neat and orderly, as we see in the following three instances where details are managed and enacted as both material and social process. We first briefly consider how different approaches to fabricating the detail of an oval aperture draw attention to digital and analog ways of knowing; followed by an in-depth exploration of the complex integration of body, talk, drawing, tools, and materials as students think through and construct the jig for a bench 
seat prototype; we then conclude with a discussion of how faculty, students, and other stakeholders mobilize individual experiences to generate a collective understanding of the truss webbing detail for a gridshell's steel edge beam.

\section{Constructing a detail: digital or analog design thinking}

A presentation at a recent conference on design-build architecture education sponsored by the American Collegiate Schools of Architecture (ACSA) serves to illustrate this entanglement. The conference had been organized and hosted by members of the Canadian research team, and was thus a privileged site for understanding how "insiders" (in this case design-build educators) viewed their own practices. The presentation, “Level and Plumb without Rhino," by Tiffany Lin (2014), focused on the disjunctures faced by her students between modeling and executing the digital and analog details for her winning design for innovative disaster relief housing, composed entirely of SIP panels (Structural Insulated Panels) (designed with her colleague Judith Kinnard). Kinnard and Lin's design featured multiple oval-shaped cutouts or apertures, which required angled tranches of PVC pipe to be inserted within the plane of the panels. According to Lin, the design and construction of the apertures generated friction between students' differently habituated "designerly ways of knowing" (Cross, 1982) especially between habits of "digital design thinking” (Oxman, 2007) and craft or material skill (Ingold, 2000; Marchand, 2016; Scott, 1998; Sennett, 2008). In this particular example, the conflict arose between fabricating a 3-D model of the apertures in the software program Rhino, and fabrication within the 3-D and gravity-governed materiality of paper, earth, tools, and PVC pipe.

Lin presented the CAD-rendered detail drawing of the apertures, marked up with dimensional measurements and material specifications. She then described how her students initially approached the problem of their fabrication. In accordance with their training, they began to make sense of the problem in Rhino (Figure 1): step 1, create a 3-D model of the pipe in Rhino and intersect it with planes; step 2, run the "Boolean Split" command, which produces a cut oval surface; step 3, because the Rhino model surface is a "ruled surface," the "unroll surface" operation generates a template on a flat plane; which, 
step 4, can then be plotted, printed at full scale on paper, and wrapped around the actual PVC pipe to mark where the cut should be made. Lin ultimately dismissed the students' approach as overwrought, then contrasted it with the advice offered by a local craftsman involved in the project. The craftsman suggested that making a level cut across the pipe was simple: since water finds its own level, put the pipe in a bathtub filled with water, mark the waterline, and cut. The architecture students ultimately modified the craftsman's method to produce a jig that ensured the consistent marking of the pipes, but the principle they used was based on the craftsman's advice.

For Lin, as for other attendees of the design-build conference, students habituated to approaching problems of design and fabrication with the logic of "digital design thinking" (in this case thinking with Rhino) presents pedagogical dilemmas for educators and implications for professional ethics (Lin, 2015). Part of the objective of design-build education is to prompt future practitioners to consider how details such as PVC apertures raise problems of scale and mediation. In other words, design-build architecture education promotes training in the

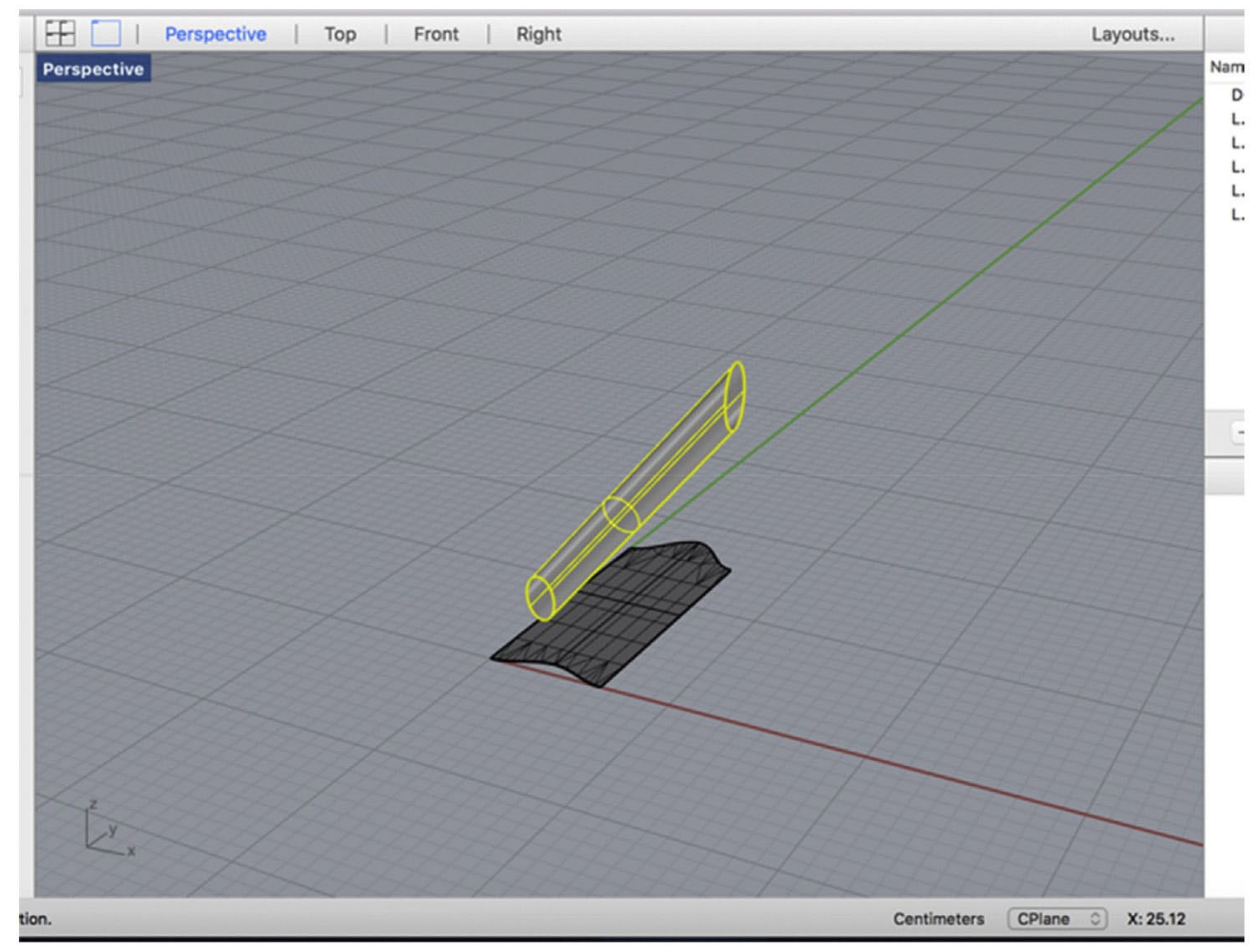

Figure 1 Re-tracing students' Rhino logic, step 3. Source: Authors' image, after Lin, 2014, slide presentation 
social and material implications of translating from a Rhino model, and the computational logic which governs the software's version of space, to full-scale materials, with their own weight, thickness, and other specific qualities, as these relate to instruments like a jigsaw, straight edge, level, and the human body. Lin's dismay at the students' reliance on "thinking with Rhino" echoes the sentiments of practicing architects in the Emirati-based design team described by Cardoso Llach (2015), and the senior engineers Loukissas (2012) spoke with at Ove Arup: a concern for a kind of intergenerational de-skilling, where younger designers, "ignore what's behind the software, the building physics" ( $\mathrm{p}$. 32). However, as Lin's case study suggests, the problem is not simply one of digital design skill and craft know-how (or lack thereof).

There are also ethical ramifications resulting from the differences between the "worlds" conjured up in the digital space of Rhino versus the 3-D space governed by the laws of physics. The differences are more than spatial: they extend to diverging logics and sequences of proper or efficient action to be taken in these worlds. The practical logics appropriate to each of these environments also emerge from and reflect different social and professional contexts inhabited by practitioners: architects, structural engineers, computer engineers, craftspersons, and others. Design-build education encourages students to question who stands to gain, or lose, from the traditional boundaries separating different practitioners, expert knowledges, and ways of working - even as these boundaries are shifting under our feet. Indeed, a central tenet of design-build education is that part of every architect's training should include a basic consideration of how a maker or craftsperson makes sense of the world of building details and materiality (Boling, 2017).

\section{Thinking through details: paper, wood, and power tools}

The art of detailing is at least partly an exercise in imagining how disparate materials and components come together. In the episode explored in this section, we are concerned as much with the social and communicative aspects of detailing, as with the design skill required to realize a construction detail at full scale. The discussion revolves around a design detail within the larger gridshell pavilion project at Southeast University in the USA. Towards the end of the semester, 
design-build studio students were working feverishly to mock-up a series of full-scale prototypes of various project details in time for the final design review. One of these prototypes was a section of bench seating (Figure 2). Two days prior to the review, a small group of students began the process of assembling a section of the bench, led by two students we call Jesse and Sarah. In what follows, we highlight how this particular detail e the materials it joined, and the collaborative efforts to make sense of its design and assembly e posed a challenge for the students. This was evidenced in the form of friction or what could be called chains of "disturbances" (Groleau, Demers, Lalancette, \& Barros, 2012) and their resolutions: errors, confusion over how to proceed, miscommunication, long silences, laughter, awkward manipulations of materials and the hesitant use of power tools.

Jesse and Sarah began development of the bench prototype in the school's workshop, with a discussion of an $11 \times 17$-inch paper printout of a series of CAD detail drawings of the bench seating, drafted

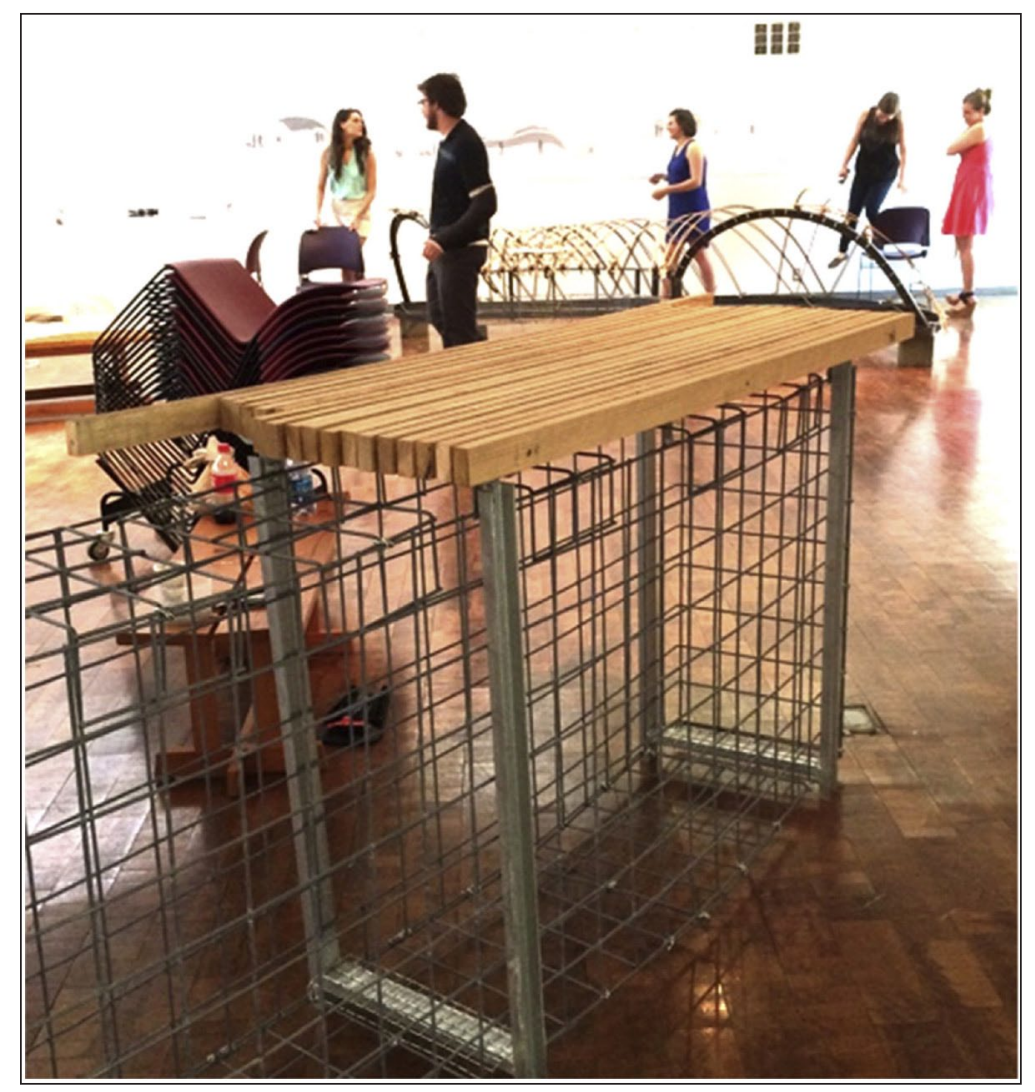

Figure 2 Finished prototype, gabion bench. Source: Authors' image 
by Jesse. They opted to mock-up a 4 -foot bench section first, drawn as a curved, slatted bench whose width was composed of 18 wooden lathes separated by spacers. The students' initial conversation concentrated on parsing Jesse's drawing, in order to imagine the materials, operations, and temporality involved in making the bench in "reality" and at full scale. In the following excerpt from their conversation, Jesse and Sarah work to establish a verbal consensus on where and how to begin, as well as on what exactly the line drawings represented in material terms:

Exerpt 1. Excerpt of interaction during design-build collaboration

Sarah: So, why don't we, why don't we start by marking out the centers ((points with index finger to detail drawing of 4-foot bench on Jesse's rendering, displayed on table between them)).

Jesse: Yeah, we don't have to worry about - the gap until it's all getting glued ((pointing with his pencil to another drawing they were discussing a moment before)).

Sarah: Right, Right.

Jesse: So, by that time we'll be done with these.

Sarah: Okay.

Jesse: So, you wanna go ahead and work on these guys? ((i.e. the lathes for the 4-foot bench)) ((Pointing with pencil to detail drawing of 4 -foot bench))

Sarah: Yeah, do those e those are going to be part of the bench, right? ((pointing to drawing))

Jesse: Yeah, it's just like the first one, and then, really, like all the pieces are like this extra thick width ((pencil points to the place where Sarah's finger touches the drawing, tracing the outer arc of the bench line on the drawing as he speaks)). So, like the longest one on this one is um ((puts down pencil to reach both hands into pockets, apparently looking for something removes empty hands from pockets and picks pencil up again)) I forgot, but I think the longest one is four foot, with the curve is like 
four foot six, so we can cut all of them five, so they're all going to be trimmed.

Sarah: ((Nods vigorously))

Jesse: So, we just need to make this one like 6 inches longer than everything else, so this one will be six ((pencil pointing to innermost lath on bench drawing, writing note on drawing as he speaks)).

Sarah: Okay. (1.o pause) So, you cut those first, cut them and plane them, and then, start marking everything? So we have everything together.

Jesse: Yeah. Cause everything goes faster when it's systematic.

In the above instance of conversation, we see the students working together to join meaning(s) (Frascari, 1984) to Jesse's draft of the bench detail. They were quickly confronted with the inherent vagueness of the line drawing: that is, it captured elements of the "what" of the bench (its basic dimensions and shape), but not the "how" of bringing it into being. At least three issues are addressed in their conversation: first, mutual confirmation of what the dimensional bench outline denotes in terms of wooden lath dimensions and configuration; second, consensus-building regarding what assembly step should happen first (ensuring some degree of joint-ownership of the fabrication process); and third, tacking back and forth in time to relate the finished prototype to the various stages of its assembly. The critical task implied, but not fully developed in the drawing, was the creation of a jig to hold the curved slats in place during bench fabrication. Jesse's drawing did not define how the jig should itself be made.

Later in the afternoon, when Jesse and Sarah took the initial steps to fabricate the jig and then put it into operation, they had to improvise: the drawing was of little assistance. Since they had decided to dry fit the bench slats in place (rather than gluing), they first had to work out how to hold the curved wood lathes in place, on the jig base (Figure 3). This improvisation included the testing of different clamping strategies: how many clamps to use, where to place them, in what sequence to accommodate each new lath, etc. The clamping "solution" they eventually decided upon produced unanticipated secondary 


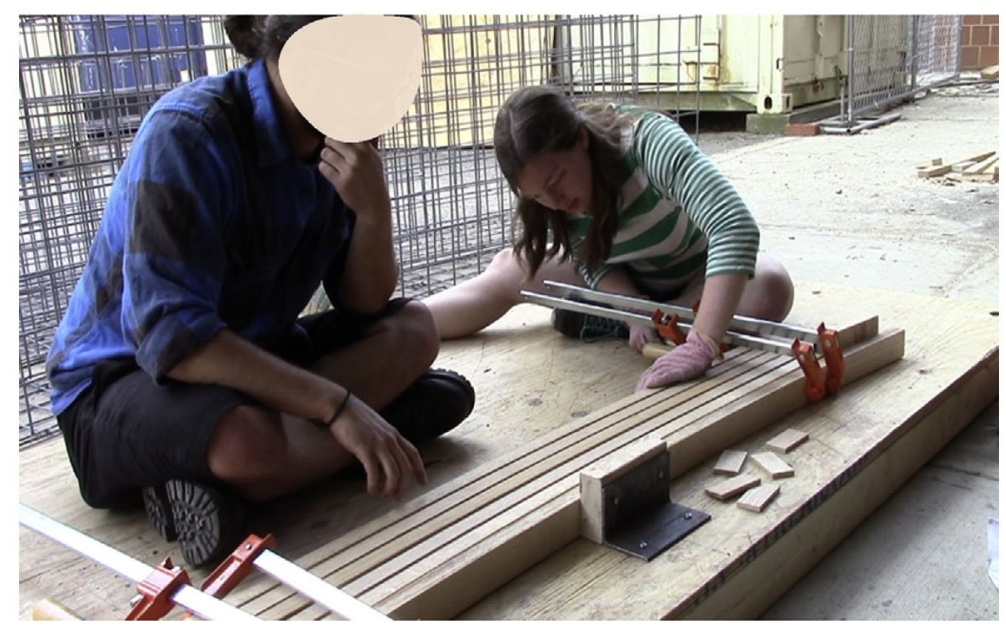

Figure 3 Students crafting bench prototype. Source: Authors' image

material and force effects e new design challenges or friction - which then had to be accounted for. In one instance, the wooden lathes on the outside curve of the bench began to lift off the surface of the jig in response to the pressure of the clamping. Jesse and Sarah decided to manage the problem by literally screwing the lathes down to the wooden jig. But that solution resulted in a later dilemma - how to remove the finished bench prototype from the jig itself. With hours to go before the design review, Jesse struggled with an angle grinder and pliers to remove these screws in order to lift the bench off the jig. One screw in particular was reluctant to let go.

\subsection{Tolerating imprecision: frictions of assembly}

The problems Jesse and Sarah encountered here relate to the inherent frictions of the detail as a joint e especially in relation to its assembly through the gathering of disparate materials, but also in the sense of a site where meaning is contested and constructed. In this case, the students were confronted with differences in the temporality of different design media e between a 2D CAD line drawing on paper and the materials for the jig and bench prototype (including Jesse and Sarah's own bodies as instruments). Given that these media each afford or invite a different order of actions, Jesse and Sarah grappled with how to interpret and orient themselves in relation to these design artifacts: that is, how to "bridge" or "tolerate" those differences. 
The CAD drawing is itself a kind of finished object: it stands at the end of a sequence of mathematical and geometric operations performed by Jesse on the computer. That "ending" was intended to guide a subsequent series of actions to make the jig and bench. This emergent and iterative quality of designing and making is widely recognized as one of the central qualities of "designerly ways of knowing" (Cross, 1982) and skilled practice more generally. In this case, the endpoint of an earlier iteration did not provide much guidance for the next. The value of sequentially segmented assembly diagrams (like IKEA drawings) is obvious to anyone who has tried to put together disparate parts to make a toy or a piece of furniture. But the CAD detail drawing presumed the involvement of an expert maker (or makers), which Jesse and Sarah were not. The students repeatedly tried to fill in those missing assembly steps over the course of several hours, during which the solution to one momentary problem created the next problem to be solved (and so on). Jesse and Sarah began with an assumption that a line drawing - the result of a relatively friction-less process of playing with "shape grammars" in CAD (Knight, 1999; Stiny, 2006) - would more or less define and facilitate the process of arranging and fixing eighteen wooden lathes in a curved bench shape. They had not bargained for the magnitude of the difference in practice.

The architectural detail is also the site where material tolerances and human capacity for precision are managed. The issue of precision, and Sarah and Jesse's mastery, or lack thereof, of power tools, compounded the challenges of working with and across different design media and their temporality. Though the students carefully marked and drilled through each of the eighteen layers of the bench slats as they went along, at the end of the process some of the holes were misaligned. To compensate for the drift of the holes, Jesse had to re-drill through all eighteen bench slats and the spacers, inserting a threaded rod to hold everything in alignment. The (mis)placement of the holes was partly a product of, as their instructor had put it earlier in the semester, "the way in which you interact with a tool, and you interact with a material, and the material interacts with the tool."

Friction of assembly then also relates to the fact that materials push back, and it takes a certain degree of experience - embodied knowledge e to be able to use a power drill as though it is an extension or prosthesis of the hand and arm. One must develop a sense for how hard to push, how to position the body and the hands for maximum 
stability, how to keep the drill level, when the sound of the drill is "not happy," etc. The making of the jig and the bench, then, is also a scene of "attunement" (Ingold, 2000), wherein the craftsman's "material consciousness" (Scott, 1998; Sennett, 2008) forms within a dynamic system of body, tools, and materials. Mastery entails a felt or embodied sense of the materials at hand, their possibilities, limits, and "behaviors." This attunement also encompasses a feel for the abilities and limitations of one's own body. By the end of their design-build studio course, ideally Jesse and Sarah would experience a seamless embodied inter-subjectivity (person plus tool plus materials), what Ihde (1990) has elsewhere referred to as an "embodiment relation" between human and technology. But at this early stage, the students encountered tools, materials, and even their own bodies as antagonistic "others," presenting an extreme form of Ihde's (1990) characterization of the "alterity relation." To return to the ethical commitments of design-build education, the objective is not to transform every student into a master craftsman. But catching even a glimpse of how details come together (or don't) prompts future architects to exercise a degree of humility, as they consider the material and social implications of their designs.

\section{Binding together: pedagogy and puzzling details}

The final episode is drawn from fieldwork among architecture students and faculty involved in the largest of the design-build gridshell projects: a pavilion constructed in a Canadian National Park. On this final project, participants from each of the North American architecture programs collaborated to design and build the structure. The large gridshell, in part because of its size and relative complexity (as compared with the smaller, local gridshells at each institution), also required intensive contributions of members of the structural engineering firm and an external design engineering consultant with gridshell experience. Geographically, members of this collaborative team spanned two continents, three countries, four times zones, at least four cohorts of students, and over three years of design development and construction. Here again, we are especially concerned with the "salutary" effects of friction (Kraus, 2017) as a detail is puzzled out: to what extent do errors, miscommunication, or confusion contribute 
(positively) to the collaborative learning process at the heart of design-build education?

To sketch the context for the following analysis, at this point in the project, the concrete foundation and walls of the structure had been poured, according to the specs of engineering-approved construction drawings, generated in part from a 3-D Rhino model. The situation we discuss below is centered around the design and fabrication of a triangular steel truss. The truss constituted the gridshell's boundary condition: the edge-beam detail joining the lattice roof to the concrete support walls. The truss is a particularly apt detail to consider in relation to teamwork and collaboration, given its structural function. For engineers, the truss is an assembly of individual members (in this case steel) whose arrangement and connections produce a rigid entity that behaves as a unified object (Plesha, Gray, \& Costanzo, 2013). At stake in the following scene is how to interpret and then realize the design of the edge-beam's truss webbing.

At the start of a day on the construction site in 2016, one of the architecture instructors gathered with a team of approximately six students around a CAD generated, printed detail drawing of the webbing pattern. The drawing had been developed by the project team's structural engineer. The professor and the project manager (a Master's student) first worked to identify which section of the truss the drawing represented (Figure 4 ). With the other students looking on,

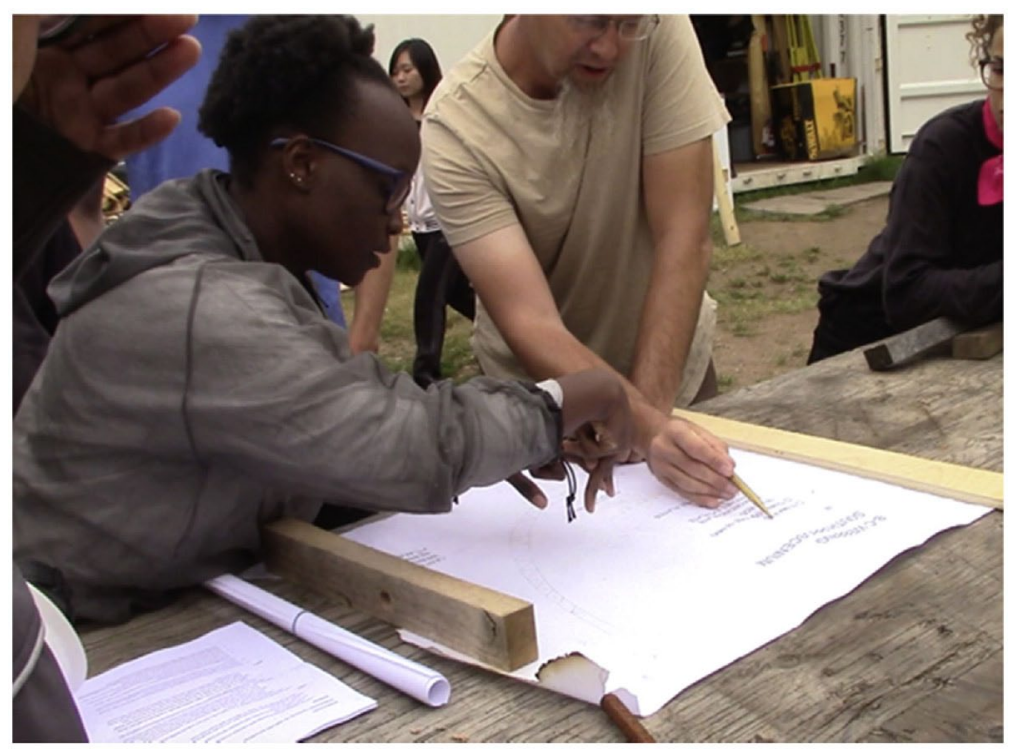

Figure 4 Professor and Project Manager parse the engineer's drawing. Source: Authors' image 
the project manager and the professor pointed at various locations on the drawing as they spoke about how the drawing related to the "real" built structure-in-progress. Speech connected finger and gesture to both the drawing and the structure, which they occasionally looked towards for reference (it was around 50-60 m away from where they were meeting). Collectively, they were having trouble understanding the relationship between the two-dimensional computer drawing and the actual, partially-completed truss edge beam. At this point, the instructor pulled out a pencil and started to sketch a more realistic, perspective rendering of the engineer's plan-view drawing. As he sketched, he labeled areas of his drawing in correspondence with those of the CAD drawing. Students and instructor then focused their discussion on comparing the two drawings. Considerable confusion ensued concerning the relationship between the computer-generated construction drawing, the pencil-drawn sketch, and the "real" partially-built metal truss.

Hoping that proximity to the edge beam might help clarify its relationship to the drawings, the group eventually re-located to a spot directly next to the structure. The printed drawing was placed on the concrete wall, while the project manager brought over her laptop, which contained an image of the Rhino model of the entire gridshell (Figure 5). The model had been created collaboratively by faculty, students, the structural engineer, and the design-engineering consultant. Several students puzzled through the problem with enthusiasm - thoughtfully expressing their ideas concerning the principles of triangular truss webbing systems. Largely drawing on memories of

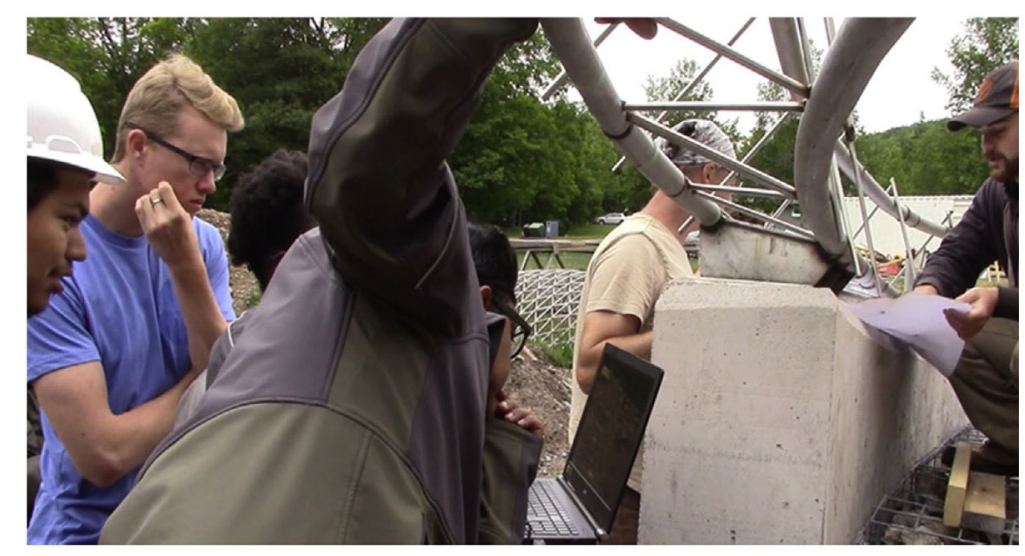

Figure 5 Students and Professor engage in sense-making on/near the gridshell. Source: Authors' image 
"structures" coursework, the majority of the students concluded that the engineer's drawing couldn't possibly be right. The instructor, still seeking to understand the incongruities between drawings and built structure, pulled out a length of orange string and tied it around one chord of the steel truss, interweaving it in the webbing configuration he believed to be correct (as he wrapped, he remarked, "Nothing like, you know, visualizing").

One student became involved in a highly-focused discussion with the instructor, gripping the metal frame and gesturing with the other hand while he explained what he thought the problem might be. In his view, the engineer's drawing did not take into account a recent change to the truss structure, from a three-faced webbing design to the substitution of a steel plate in place of one side of the triangular truss. The professor considered this opinion carefully by checking the student's words: "alright, so you're saying it's plausible if you didn't have the plate and since you have the plate it's okay?" to which the student replied "right, the plate resolves." While considering this proposal, the professor climbed on the structure, took a series of iPhone photos of the string (as a possible webbing pattern), and emailed these to the engineer. The response from the engineer arrived a few hours later: he had determined that the original webbing pattern (on his construction detail drawing) was derived from the standard design of a triangular truss. It dated from a time when the gridshell's proposed truss respected that standard. As the student had suspected, in subsequent design phases, the architectural members of the design team had decided to substitute a metal plate for one side of the truss. But the engineer's model hadn't been updated to reflect this. In the end, the engineer noted that to alter the webbing pattern for what the architects thought would be a more satisfying "aesthetic" reason would require another week or more to re-model and re-test the structure. From their position onsite, the group decided to follow the original webbing design, which they would use in addition to the steel plate.

\subsection{Joint ownership of the detail}

From beginning to end, the time it took to identify and then resolve the lack of correspondence between the computer-generated detail drawing and the "in the flesh" structure lasted several hours. The interaction and engagement with the webbing detail, as materialized 
across various design media, followed a somewhat circuitous path, but it illustrates the myriad tactics architects employ to reason and make sense of the best way forward, given the "plans" charted in the past by others (i.e. the engineers, or even previous versions of themselves). To return to the specificity of the gridshell and its innovative qualities, this episode demonstrates the nature of collaborative sensemaking in the face of multiple unknowns. The gridshell is not a common structural typology that participants would be familiar with from previous experience, or that can be extrapolated from existing precedents in a straightforward manner. Making sense of a truss detail, which has standard configurations in "normal" structures, required particularly intensive actions of a collective "puzzling through."

This nonlinear approach to achieving interpretive consensus around the enigmatic truss detail (in all its versions) is also central to the pedagogical logic of design-build education in general. Circumstances of uncertainty and disjuncture are not just questions of architectural intent or vision. In design-build, these are simultaneously material and social questions. This is evident in the mutual engagement of faculty, students, and engineer in the processual reconciling of multiple opinions, opinions informed by varying levels of skill and of experience and history with this particular project. In hindsight, the group could have proceeded with the engineer's webbing design and saved considerable time. But we argue against understanding this episode as a waste of time. Part of what was pieced together in the interactions recounted here was a more comprehensive understanding of how and why decisions were taken in the first place. In a sense, the instructor and students pooled their highly specific individual knowledge and experience with the project as a whole, and the truss detail in particular, to reverse engineer the design decision-making process. This enabled them to achieve consensus about how to move forward - further cementing (forgive the pun) the social bonds among the group members - not an inconsequential thing for a project of this nature.

Indeed, intra-group cohesion was fostered partly through the overt performance of misunderstanding and incomprehension by the tenured professor (and expert on structural forms), as he conversed with a Master's student (the project manager) and several undergraduate students. Because the professor conveyed his genuine inability to make sense of how the CAD drawing related to the built structure, the students were authorized to fully engage in solving the problem alongside 
him. All participants grappled with the matters at hand; they came to collectively "own" the puzzle of the webbing detail. And this, despite only arriving at a partial understanding of what was likely going on (their understanding was eventually confirmed later by the engineer: i.e. that the drawing they had been referencing had not taken account of a panel that replaced one face of the triangular truss). Students also witnessed a model of/for a "design-build" approach to problems. When confronted with confusion, the professor persisted in bringing all faculties to bear upon his goal to understand e in the form of hand drawing, gesturing, engaging with the "real" structure, measuring, wrapping string, and seeking and listening to the contributions of others. While the professor ultimately relied on confirmation from the engineer, who he clearly trusted (at one point as he spoke with the students he described the engineer as "totally solid"), he first enlisted student involvement in puzzling through the discrepancies between drawing and built structure. What emerged was a kind of humility of discovery, joining human participants, hand and computer-generated drawings, and the irrefutable solidity of the as-built (though incomplete) welded-steel truss.

\section{Tying up loose ends}

Together, the three instances addressed in this paper highlight the sociomaterial qualities of the detail and its role in the architectural endeavor. First, we considered the ethical positioning of design-build vis-_a-vis professionalization and hand/digital craft, where efforts to bridge the design-construction divide come to the fore in the realization of the detail. Second, we examined the socio-material and embodied dimension of detail design and fabrication, where students are obliged to work across and with various design media and materials (including the design and use of jigs). An ethnomethodologically-informed ethnography of architecture practice illuminates the nuanced relationships that novice (and expert) architects develop with tools, materials, design media, and their own bodies. Third, we emphasized the intersubjective and communicative aspects of designing and building with others. The example of the truss webbing detail highlighted how the disjunctures between design media, and the misunderstandings and uncertainty they generated, facilitated both 
student engagement and learning. The "not knowing" that features in the designing and building of innovative structures like gridshells means that practitioners - including senior professors - may openly display their discomfort through "live performances" of uncertainty and bewilderment. These may occur as frequently as the more comforting display of resolution and understanding. We argue that if, at first glance, these instances of friction are undesirable, they are in fact central to the pedagogical model of design-build education. Given the nature of design-build education, where students and instructors collaborate at all levels of a project (and often include external stakeholders such as engineers and clients), it is in the professor's performance of managing confusion that some of the most profound lessons of architecture may be learned.

Taken as a whole, these vignettes affirm the "salutary" effects of details that at least initially fail to cohere. In other words, we propose that disjunctures, uncertainty, and confusion should not be treated as problems with the pedagogy (and therefore to be eliminated), but rather as integral to the logic of designbuild education. Of course, embracing such diversity involves messiness and risk. As revealed in our discussion, this occurs both at the level of confusion concerning materials, tools, bodies, and design media, but also at the level of social interaction and role performance. In these circumstances, we see how understanding is created over time, alongside and through materials (PVC pipe, wooden slats, steel webbing), tools (jigs, clamps, drills, string, embodied gestures (pointing, grasping, grimacing, measuring, reading), and discursive action (conversation, laughter, cursing). This points to the profoundly social dimensions of designing and building with multiple others.

Returning to the ambivalent status of the detail, in this paper we have explored the productive qualities of "the devil in the details," or joinings which resist, not in pursuit of an environment built according to principles of "zero tolerance" (a goal of dubious merits (Kolarevic, 2014)) or the training of autonomous architects with total control over detailing, tolerances, and therefore construction (Baudoin, 2016). The contingent nature of the social and material interactions within which the doing of architecture is embedded precludes such an outcome. Instead, jumping off from Jeremy Till's (2009) formulation of architecture as a discipline defined by its dependency on the contingencies of external forces, we suggest that tolerance of the material and social 
frictions of architecture might be viewed as an opportunity and not a threat for its practice (p. 151). While this paper has focused exclusively on architectural education contexts, where risk and failure are integral to the learning process, the lessons of the detail have implications for professional practice as well. Most significantly, "mastery" of the interdependency and messiness of designing and building with others might look like moments of humility, of confusion, or of sharing or delegating power, and so instances of professional practice may greatly benefit by setting up channels through which dissent, debate, and multiple opinions are heard and taken into account. smart phones), representations (drawings on paper and on a laptop screen),

Funding - This work was supported by a Social Sciences and Humanities Research Council of Canada Partnership Grant.

Declaration of Competing Interest - The authors declare that they have no known competing financial interests or personal relationships that could have appeared to influence the work reported in this paper.

Acknowledgments - We acknowledge and appreciate the support of Canada's Social Sciences and Humanities Research Council in carrying out and disseminating this research. We also thank the participants in this research for their contributions and good natured "tolerance" of the presence of two social scientists.

\section{References}

Anderson, J. (2014). Woodland creatures and fabrication wizards. Resources, product, context and motivation observed in a taxonomy of live projects. In $A A E$ 2014 Conference proceedings (pp. 227e232).

Baudoin, G. (2016). A matter of tolerance. The Plan Journal 33e46.

Boling, T. (2017). Embodied making: Designing at full scale. In C. Kraus (Ed.), Designbuild education (pp. 140e153). London: Routledge.

Burry, M. (2014). The architectural detail and the fear of commitment. Architectural Design, 4(230), 134e141.

Cardoso Llach, D. (2015). Builders of the vision: Software and the imagination of design. London: Routledge.

Cavanagh, T. (2013). Innovative structures and the design-build model of teaching. In A. Zarzycki, \& R. J. Dermody (Eds.), Tectonics of Teaching, Proceedings of the 2013 Building Technology Educators' Society Conference (pp. 405e411). Building Technology Educators' Society Conference. 
Chilton, J., \& Tang, G. (2016). Timber gridshells: Architecture, structure and craft. London: Routledge.

Cross, N. (1982). Designerly ways of knowing. Design Studies, 3(4), $221 \mathrm{e} 227$.

Douthe, C., Baverel, O., \& Caron, J. F. (2006). Form-finding of a grid shell in composite materials. Journal of the International Association for Shell and Spatial Structures, 47(50).

Eames, C. (1961). Eames Contract Storage. In D. Ostroff (Ed.), An Eames anthology: Articles, film scripts, interviews, letters, notes, and speeches (pp. 224e225). New Haven: Yale University Press, Original work published 1961.

Farias, I., \& Wilkie, A. (Eds.). (2016). Studio studies: Operations, topologies \& displacements. London: Routledge.

Ford, E. (2011). The architectural detail. New York: Princeton Architectural Press.

Frampton, K. (1995). Studies in tectonic culture: The poetics of construction in nineteenth and twentieth century architecture. Cambridge, MA: MIT Press.

Frascari, M. (1984). The tell-the-tale detail. In VIA 7: The Building of architecture (pp. 23e37).

Gjertson, W. G., \& Trumble, C. (2014). Design-build gone south, working out: Thinking while building. ACSA Fall Conference Proceedings 194e200.

Groleau, C., Demers, C., Lalancette, M., \& Barros, M. (2012). From hand drawings to computer visuals: Confronting situated and institutionalized practices in an architecture firm. Organization Science, 23(3), 651e671.

Hardin, M., Eribes, R., \& Poster, C. (Eds.). (2005). From the studio to the streets: Service-learning in planning and architecture. Sterling, VA: Stylus Publishing.

Harriss, H., \& Widder, L. (Eds.). (2014). Architecture live projects: Pedagogy into practice. London: Routledge.

Holstein, J., \& Gubrium, J. (2007). Constructionist impulses in ethnographic fieldwork. In J. Holstein, \& J. Gubrium (Eds.), Handbook of constructionist research (pp. 373e395). London: The Guilford Press.

Ihde, D. (1990). Technology and the lifeworld. Bloomington/Minneapolis: Indiana University Press.

Ingold, T. (2000). Perception of the environment: Essays on livelihood, dwelling and skill. London: Routledge.

Ingold, T. (2013). Making: Anthropology, archaeology, art and architecture. New York: Routledge.

Knight, T. (1999). Shape grammars in education and practice: History and prospects. International Journal of Design Computing, 2. http://www.mit. edu/ tknight/IJDC/.

Kolarevic, B. (2014). Why we need architecture of tolerance. Architectural Design, 1(227), 128e132.

Kraus, C. (Ed.). (2017). Designbuild education. London: Routledge.

Liddell, I. (2015). Frei Otto and the development of gridshells. Case Studies in Structural Engineering, 4, 39e49. 
Lin, T. (2014). Level and plumb without Rhino: Problem solving issues of making beyond the digital realm. In Working out: Thinking while building, ACSA Fall 2014 conference, Halifax, NS, 16-18 October. ACSA.

Lin, T. (2015). Level and plumb without Rhino: Problem solving issues of making beyond the digital realm. In Working out: Thinking while building. ACSA fall 2014 conference proceedings (pp. 555e562). Washington, D.C.: ACSA Press.

Loukissas, Y. (2012). Co-Designers: Cultures of computer simulation in architecture. London: Routledge.

Malek, S. R. (2012). Doctoral Dissertation. The effect of geometry and topology on the mechanics of grid shells. Massachusetts Institute of Technology.

Marchand, T. (Ed.). (2016). Craftwork as problem solving: Ethnographic studies of design and making. Farnham, surrey: Ashgate.

McCarter, R. (2005). Louis I. Kahn. New York: Phaidon.

Murphy, K. M. (2012). Transmodality and temporality in design interactions. Journal of Pragmatics, 44, 1966e1981.

Nicholas, C., \& Oak, A. (2018). Building consensus: Design media and multimodality in architecture education. Discourse and Society, 29(4), $436 \mathrm{e} 454$.

Oak, A. (2011). What can talk tell us about design? Analyzing conversation to understand practice. Design Studies, 32(3), 211e234.

Oak, A. (2012). "You can argue it two ways": The collaborative management of a design dilemma. Design Studies, 33(6), $630 \mathrm{0} 648$.

Oxman, R. (2007). Digital architecture as a challenge for design pedagogy: Theory, knowledge, models and medium. Design Studies, 29, 99e120.

Oxman, R., \& Oxman, R. (2010). New structuralism: Design, engineering and architectural technologies. Architectural Design, 8o(4), $14 \mathrm{e} 23$.

Plesha, M. E., Gray, G. L., \& Costanzo, F. (2013). Engineering mechanics: Statics (2nd ed.). New York: McGraw-Hill Companies Inc.

Rockhill, D., \& Kraus, C. (2017). Work ethic, ethical work. In C. Kraus (Ed.), Designbuild education (pp. 214e230). London: Routledge.

Scott, J. (1998). In Seeing like a state: How certain schemes to improve the human condition have failed. New Haven: Yale University Press.

Sennett, R. (2008). The craftsman. New Haven: Yale University Press.

Stiny, G. (2006). Shape: Talking about seeing and doing. Cambridge, MA: The MIT Press.

Suchman, L. (2006). Human-machine reconfigurations: Plans and situated actions (2nd ed.). Cambridge: Cambridge University Press.

Tang, G. (2013). Timber gridshells : Beyond the drawing board. Proceedings of the Institution of Civil Engineers. Construction Materials, 166(6), $390 \mathrm{e} 402$.

Till, J. (2009). Architecture depends. Cambridge, Mass: MIT Press.

Verderber, S. (2019). Territories of educational design/build. In Thinking while doing: Explorations in educational design/build (pp. 29e46). Boston: De Gruyter. 
Verderber, S., Cavanagh, T., \& Oak, A. (Eds.). (2019). Thinking while doing: Explorations in educational design/build. Boston: De Gruyter.

Yaneva, A. (2009). The making of a building: A pragmatist approach to architecture. London: Peter Lang.

Yaneva, A. (2012). Mapping controversies in architecture. London: Ashgate Publishing. 